\title{
From metamorphosis to maturity in complex life cycles: equal performance of different juvenile life history pathways
}

\author{
Benedikt R. Schmidt, ${ }^{1,2,6}$ Walter Hödl, ${ }^{3}$ and Michael Schaub ${ }^{4,5}$ \\ ${ }^{1}$ Institut für Evolutionsbiologie und Umweltwissenschaften, Universität Zürich, Winterthurerstrasse 190, 8057 Zürich, Switzerland \\ ${ }^{2}$ KARCH, Passage Maximilien-de-Meuron 6, 2000 Neuchâtel, Switzerland \\ ${ }^{3}$ Department für Evolutionsbiologie, Universität Wien, Althanstrasse 14, 1090 Vienna, Austria \\ ${ }^{4}$ Division of Conservation Biology, Institut für Ökologie und Evolution, Universität Bern, Baltzerstrasse 6, 3012 Bern, Switzerland \\ ${ }^{5}$ Schweizerische Vogelwarte, 6204 Sempach, Switzerland
}

\begin{abstract}
Performance in one stage of a complex life cycle may affect performance in the subsequent stage. Animals that start a new stage at a smaller size than conspecifics may either always remain smaller or they may be able to "catch up" through plasticity, usually elevated growth rates. We study how size at and date of metamorphosis affected subsequent performance in the terrestrial juvenile stage and lifetime fitness of spadefoot toads (Pelobates fuscus). We analyzed capture-recapture data of $>3000$ individuals sampled during nine years with mark-recapture models to estimate first-year juvenile survival probabilities and agespecific first-time breeding probabilities of toads, followed by model selection to assess whether these probabilities were correlated with size at and date of metamorphosis. Males attained maturity after two years, whereas females reached maturity 2-4 years after metamorphosis. Age at maturity was weakly correlated with metamorphic traits. In both sexes, first-year juvenile survival depended positively on date of metamorphosis and, in males, also negatively on size at metamorphosis. In males, toads that metamorphosed early at a small size had the highest probability to reach maturity. However, because very few toadlets metamorphosed early, the vast majority of male metamorphs had a very similar probability to reach maturity. A matrix projection model constructed for females showed that different juvenile life history pathways resulted in similar lifetime fitness. We found that the effects of date of and size at metamorphosis on different juvenile traits cancelled each other out such that toads that were small or large at metamorphosis had equal performance. Because the costs and benefits of juvenile life history pathways may also depend on population fluctuations, ample phenotypic variation in life history traits may be maintained.
\end{abstract}

Key words: age-specific breeding probability; amphibian; cohort iteroparity; compensatory growth; complex life cycle; life history transition; maturity; metamorphosis; Pelobates fuscus; sex-specific life histories; size; survival.

\section{INTRODUCTION}

Maturation divides a life history into preparation and fulfillment (Stearns 1992). In species with complex life cycles, metamorphosis is a further major life history transition that divides the "preparation" stage (Wilbur 1980). Yet, neither metamorphosis nor maturity are new beginnings because performance in one stage can affect performance in later stages. Variation in environmental conditions often creates variation among individuals in growth and size (Lindström 1999, Beckerman et al. 2002, Cam et al. 2003). Animals that start a new life stage at a smaller size than conspecifics may either always remain smaller or they may be able to "catch up" in some way such that they reach a later life cycle stage at the same size as the conspecifics that were initially

Manuscript received 17 May 2011; revised 22 September 2011; accepted 5 October 2011. Corresponding Editor: S. P. Lawler.

${ }^{6}$ E-mail: benedikt.schmidt@ieu.uzh.ch larger (Lindström 1999, Metcalfe and Monaghan 2001). Small individuals of many species sometimes compensate for a start at a small size through enhanced growth (Metcalfe and Monaghan 2001) or smaller individuals may allocate resources differently during adulthood such that they can compensate for poor conditions earlier in life (Auer 2010). While the mechanism underlying compensation in most studies is based on plasticity in growth rates or energy allocation, we describe a different mechanism. Studying the juvenile life history of an amphibian, we test whether small and large individuals follow different life history pathways where the effects of different metamorphic traits on maturity cancel each other out (Dobzhansky 1956). Such a "cancelling out" may lead to equal performance such that there are no long-term effects of a bad start.

Recent theory shows that a full understanding of the evolutionary ecology of complex life cycles requires that we better understand the juvenile stage. Population models converged on the conclusion that the juvenile stage is most important because it largely determines 
population growth rate (Lampo and De Leo 1998, Hels and Nachman 2002, Conroy and Brook 2003). Our interest was to comprehensively analyze and quantify the effects of variation in metamorphic phenotype (i.e., date of and size at metamorphosis) on first-year juvenile survival, patterns of maturation and fitness (as measured by population growth rate $\lambda$ ). We focus on the juvenile stage of amphibians where we can build upon a substantial body of previous research (e.g., Smith 1987, Semlitsch et al. 1988, Berven 1990, Goater 1994, Scott 1994, Morey and Reznick 2001, Altwegg and Reyer 2003); we note that similar effects of larval performance on subsequent performance have been reported in wide variety of invertebrates (Benard 2004, Pechenik 2006). As previous studies showed, performance in the larval aquatic environment, as measured by the metamorphic phenotype, is likely to affect performance in later terrestrial stages. This relationship is not universal, however, or it may be limited to a short period of time (McPeek and Peckarsky 1998, Boone 2005, De Block and Stoks 2005, Chelgren et al. 2006). In amphibians, long periods of post-metamorphic growth are the rule; maturity is often delayed and attained at different ages by individuals from the same cohort (Bell 1977, Werner 1986). This may allow the growth trajectories of individuals of large and small size at metamorphosis to partially or fully converge (Goater 1994, Boone 2005).

We quantify the effects of date of and size at metamorphosis on juvenile first-year survival and maturation in the spadefoot toad, Pelobates fuscus (see Plate 1). We include in our analysis all the traits that were previously identified as being important and we do the analysis separately by sex. In order to learn whether effects of metamorphic phenotype and different trait combinations lead to lasting performance differences or whether effects of different metamorphic traits on maturity cancel each other out (Dobzhansky 1956), we calculate the probability to attain maturity and use a Leslie matrix approach to assess the fitness consequences of different combinations of metamorphic traits (Caswell 2001). We show that date of and size at metamorphosis had effects on subsequent performance but ultimately has no lasting effects because it led to different life history pathways with similar fitness. This contrasts with the widely held view that larval conditions have lasting effects on post-metamorphic performance (Lindström 1999, Pechenik 2006).

\section{Materials and Methods}

\section{The spadefoot toad Pelobates fuscus}

The European spadefoot toad (Pelobates fuscus fuscus Laurenti 1768) is a pelobatid toad found primarily in the lowlands of central and eastern Europe. Outside the breeding season, it is mainly fossorial and emerges from its underground burrows at night for foraging. Unlike North American spadefoot toads (Spea sp. and Scaphiopus sp.), which prefer temporary ponds, Pelobates fuscus congregate during spring in permanent ponds for reproduction (Van Buskirk 2003). Pelobates fuscus is an explosive breeder (Hels 2002). Breeding usually occurred in April and/or May with a peak breeding activity that lasted for about one month (Hödl et al. 1997).

\section{Study site and data collection}

We captured juvenile and adult spadefoot toads using a drift fence that completely encircled a permanent pond on an island of the Danube river near Vienna, Austria, during nine consecutive years from 1989 to 1997 (Hödl et al. 1997). The fence was checked daily throughout the year, and captures were made both when toads entered the pond and when they left the pond. The drift fence was placed very close to the pond edge $(\sim 1 \mathrm{~m})$. There are other small ponds on the island, but they were only constructed in 1994 and only a single female P. fuscus marked at the study site was ever found at another pond (Hödl et al. 1997). Thus, emigration has a negligible effect on our results.

In total, we captured 3113 individuals of P. fuscus. At the time of first capture and marking, 2758 were metamorphs and 355 were adults (165 males and 190 females). Metamorphs emerged from the pond long after all adults had left the pond. Of the metamorphs, 467 were recaptured as adult toads (261 males and 206 females) whereas 2291 individuals captured shortly after metamorphosis were never seen again and remained unsexed. Each individual was photographed for later identification. Some toads were marked with a PIT tag as adults (Jehle and Hödl 1998, Gibbons and Andrews 2004). An analysis of double marked adult toads showed that there was no misidentification (R. Jehle, personal communication).

Body mass was measured to an accuracy of $0.1 \mathrm{~g}$, and snout-vent length (size) was measured to an accuracy of $0.1 \mathrm{~cm}$. Because the pit falls at the drift fence were checked daily, the date of first capture of the metamorphs was considered to be the date of metamorphosis. Many metamorphs had not yet fully resorbed the tail when they were captured. For metamorphs, we analyzed data from five annual cohorts of metamorphs (years 1989-1993) to ensure that all individuals had a nonzero chance to mature and to be recaptured during the study period. The number of captured individuals varied between years (for metamorphs, 1989, 134; 1990, 235; 1991, 1373; 1992, 603; 1993, 413; for adults, 1989, 93; 1990, 40; 1991, 26; 1992, 26; 1993, 20; 1994, 49; 1995, 59; 1996, 14; 1997. 28). Further details of the methods and additional data are given in Appendix A, Jehle et al. (1995), Hödl et al. (1997), and Jehle and Hödl (1998).

\section{Correlations between metamorphosis and body condition at maturity}

Body mass and size at metamorphosis were highly and positively correlated $(r=0.81)$. We used the scores of the first axis of a principal component analyses of body 
mass and size as an index of metamorph body condition ( $\mathrm{PC}_{\text {meta }}$; Altwegg and Reyer 2003). $\mathrm{PC}_{\text {meta }}$ explained $95 \%$ of the variance and both mass and size had positive loadings (0.32 and 0.94, respectively). We used model selection based on regression analysis (Burnham and Anderson 2002) to study the relationship between date and body condition at metamorphosis and body condition at maturity, treating each sex separately (Appendix B: Table B1).

\section{Analysis of mark-recapture data}

We used multistate mark-recapture models to estimate apparent survival and age at first reproduction (Clobert et al. 1994, Pradel and Lebreton 1999, Cam et al. 2005, Lebreton et al. 2009) with two states: metamorph and breeder. All individuals that were captured at metamorphosis are in the state "metamorph," and all individuals that were either recaptured or that were initially captured as breeder are in the state "breeder." Once an individual has been captured as a breeder, it will remain in that state even if it skips breeding in some years. The transition probabilities between states are the age-specific probabilities of first time reproduction $(a)$, i.e., the transition from state "metamorph" to the state "breeder." Besides the usual assumption of multistate mark-recapture models (Lebreton et al. 2009), the model assumes that survival during the first year after metamorphosis differs from survival later. Hence, we assume that all individuals older than 1 year have the same survival probability irrespective of whether they have started to reproduce (this is the pattern of survival that McCaffery and Maxell [2010] reported for a pond-breeding frog). Moreover, the model assumes a fixed age where all individuals have started to breed. We used model selection to evaluate at which age full reproduction is reached (Clobert et al. 1994).

The model has three different parameter types: $\phi_{m, i}$ is the probability that an individual of age $m$ that is alive at sampling occasion $i$ is still alive and has not permanently emigrated from the population at sampling occasion $i+$ $1, \alpha_{m, i}$ is the probability an individual of age $m$ years reproduces for the first time at sampling occasion $i$ (i.e., the age-specific transition probability from state "metamorph" to state "breeder"), and $p_{i}$ is the probability that a marked individual in the state "breeder" that is alive at sampling occasion $i$ is at the pond and recaptured at sampling occasion $i$. See Appendix $\mathrm{C}$ for the matrix notation of the model. The most general model that we considered had different survival probabilities $(\phi)$ for each of the two age classes, for each time period and for each sex. The probabilities of age-specific first time reproduction $(\alpha)$ differed between sexes, and we initially fixed the age of full breeding to age of 6 years. The recapture probabilities of breeders $(p)$ were time and sex specific. We denote this model as $\{\phi[\mathrm{a} 2 \times \operatorname{sex} \times t], \alpha[\mathrm{a} 6 \times$ sex], $p[\operatorname{sex} \times t]\}$, where $a x$ refers to an age effect with $x$ age classes, $t$ refers to time dependence (different years), and sex refers to a sex effect.

No goodness-of-fit (GOF) test is available for our model. However, a model with time-specific survival and recapture probabilities for a cohort does in fact account for all heterogeneity introduced by age- and time-specific variation in survival, time of first reproduction, and recapture. Thus, we conducted a goodness-of-fit test with program U-CARE (Choquet et al. 2009) for the model $\{\phi[$ cohort $\times \operatorname{sex} \times t, p[$ cohort $\times \operatorname{sex} \times t]\}$ for all toads first marked as metamorphs and for the model $\{\phi[\operatorname{sex} \times t], p[\operatorname{sex} \times t]\}$ for all toads first marked as breeder. The fit of this model was acceptable (for metamorphs, $\chi_{13}^{2}=14.89, P=0.314$; for breeders, $\chi_{22}^{2}=$ 33.60, $P=0.054$; overall, $\left.\chi_{35}^{2}=48.49, P=0.064\right)$. Yet, the GOF revealed some overdispersion, and we used a variance inflation factor $(\hat{c}=1.385)$ to adjust model selection criteria and standard errors of the parameters (Burnham and Anderson 2002).

Because of the complexity of the model, the analysis was performed in several steps. Within the first modeling step, we evaluated the most parsimonious structure of recapture, age-specific probability of first breeding, age when all toads have started to breed, and survival; candidate models are shown in Tables B2-B10 in Appendix B. The most complex model for recapture probability allowed for effects of sex and time. To estimate the age at which all individuals started to reproduce, we fitted models in which this age varied from 1 to 6 years; we also tested for variation among cohorts in the age when all individuals have started to reproduce. The most general structure for survival probabilities considered sex- and time-specific variation in first-year juvenile and adult (i.e., after first-year) survival.

The goal of the second modeling step was to assess whether and how date of and body condition at metamorphosis correlated with age-specific breeding probabilities and juvenile first-year survival. While modeling individual covariates, we kept all parameters but the focus parameter at the best structure determined in step one (details are given in the table captions), and only modeled the key parameter.

Because our intention was to estimate sex-specific first-year juvenile survival, we had to know the sex of metamorphs that were never recaptured. Because toads could not be sexed at metamorphosis, we only know the sex of individuals that were captured as adults. We estimated the probability that a given individual is a male by using information about sex-specific differences of size and body mass at metamorphosis (see Results), and under the assumption that the sex ratio at metamorphosis is even. We conducted a logistic regression in which sex was the dependent variable and size and body mass the independent variables. The regression coefficients (intercept $=-1.655 \pm 1.749$ [mean $\pm \mathrm{SE}]$, size $=0.040 \pm 0.072$, body mass $=0.130 \pm 0.179$, $n=467$ individuals) were used to calculate the 
probability that the unsexed individual $j$ with size $s_{j}$ and body mass $\mathrm{bm}_{j}$ was a male $\left[p\left(m_{j}\right)\right]$, or a female $\left[p\left(f_{j}\right)=1\right.$ $-p\left(m_{j}\right)$. Because the morphological differences among sexes were small, these regression slopes were rather shallow and had large standard errors. Consequently the probability that a metamorph of unknown sex was a male was often predicted to be close to 0.5 . We also included the assumption that the sex ratio at metamorphosis was even using the following calculation. The total number of metamorphs in cohort $i$ was $R_{i}$, of which a subset was later recaptured as males $m_{i}$ and females $f_{i}$, respectively. Thus, of the $R_{i}-m_{i}-f_{i}$ unsexed individuals $0.5\left(R_{i}-m_{i}\right)$ individuals must be males and $0.5\left(R_{i}-f_{i}\right)$ must be females if the sex ratio is even. The number of unsexed males at metamorphosis of cohort $i$ based on the logistic regression is $\Sigma p\left(m_{j}\right)$, but should be $0.5\left(R_{i}-\right.$ $\left.m_{i}\right)$. Hence, the probability that individual $j$ is a male is $M_{j}=p\left(m_{j}\right)\left[0.5\left(R_{i}-m_{i}\right)\right] / \Sigma p\left(m_{j}\right)$, and that it is a female $F_{j}$ $=1-M_{j}$. A simulation study showed that unequal sex ratios (11:13) cause small relative bias in first-year juvenile survival estimates ( $\pm \sim 8 \%$; Appendix E). Only strong sex ratio bias $(1: 2)$ caused substantial relative bias $( \pm \sim 30 \%$ ) in estimates of first-year juvenile survival. Juvenile first-year survival of the rarer sex was overestimated whereas juvenile survival of the commoner sex was underestimated (Appendix E). Adult survival and probability of first time reproduction were always unbiased. We are unaware of published evidence for sex ratio bias at metamorphosis in anurans under natural conditions.

We used program MARK (White and Burnham 1999) to conduct the capture-recapture analyses, and performed model selection using $\mathrm{AIC}_{\mathrm{c}}$ (Burnham and Anderson 2002). All estimates derived from markrecapture analyses were subject to model averaging.

\section{Probability to mature and population growth rate}

Based on the estimated age-specific survival probabilities $\left(\phi\left[\right.\right.$ age, $\mathrm{PC}_{\text {meta }}$, date]) and age-specific probabilities to reproduce for the first time ( $\alpha\left[\right.$ age, $\mathrm{PC}_{\text {meta }}$, date]), we calculated the probability $\left(p_{\mathrm{m}}\right)$ that a male metamorph with body condition $\left(\mathrm{PC}_{\text {meta }}\right)$ and date of metamorphosis (date) would survive to maturity:

$$
\begin{aligned}
& p_{\mathrm{m}}\left[\mathrm{PC}_{\text {meta }}, \text { date }\right] \\
& =\phi\left[1 y, \mathrm{PC}_{\text {meta }}, \text { date }\right] \\
& \times\left[\alpha\left[1, \mathrm{PC}_{\text {meta }}, \text { date }\right]\right. \\
& \quad+\sum_{i=2}^{z}\left(\phi_{\mathrm{ad}}^{i-1} \alpha\left[i, \mathrm{PC}_{\text {meta }}, \text { date }\right]\right. \\
& \left.\left.\quad \times \prod_{j=1}^{i-1}\left(1-\alpha\left[j, \mathrm{PC}_{\text {meta }}, \text { date }\right]\right)\right)\right]
\end{aligned}
$$

where $\alpha\left[\mathrm{z}, \mathrm{PC}_{\text {meta }}\right.$, date $]=1$ and $\phi_{\mathrm{ad}}$ is adult annual survival.
To estimate fitness in relation to body condition at metamorphosis and date of metamorphosis, we formulated a post-breeding census, female-based, matrix projection model with five age classes (toadlet, 1 year old, 2 year old, 3 year old, more than 3 years old) and a projection interval of one year to calculate the dominant eigenvalue of the projection matrix as an estimate of the asymptotic population growth rate, and thus of fitness of females (Caswell 2001).

To parameterize the model, we used survival probabilities and probabilities to start reproduction estimated in this study, whereas for tadpole survival and clutch size we used values from the literature on Pelobates fuscus (Hels 2002, Hels and Nachman 2002). While tadpole survival is density-dependent (Hels and Nachman 2002), clutch size is positively correlated with body mass of females, and older females have larger clutches than young females (Hels 2002). We calculated population growth rate (i.e., fitness) for females with low, medium, and high body condition (index -2, 0, 2) and early, medium and late timing of metamorphosis (14 July, 8 August, 12 September). The model assumes equal survival during the larval stage for small and large metamorphs and for those that metamorphose early and late. The model therefore compares the fitness of individuals that metamorphose early or late and at small or large size. Given that the fate of juveniles determines the fate of spadefoot toad populations (Hels and Nachman 2002), this approach seems justified. We estimated confidence intervals for the probability to reach maturity and population growth rate in $\mathrm{R}$ ( $\mathrm{R}$ Development Core Team 2009) using simulation code available in the electronic appendix to Schaub et al. (2009). Further details are provided in Appendix D.

\section{RESUlts}

\section{Metamorphosis}

Across all years, average mass of metamorphic spadefoot toads $(n=2758)$ was $4.46 \mathrm{~g}(\mathrm{SD} 0.89 \mathrm{~g})$, mean length was $32.18 \mathrm{~mm}$ (SD $2.24 \mathrm{~mm}$ ), and mean date of metamorphosis was 15 August $(\mathrm{SD}=13.16 \mathrm{~d}$, Fig. 1). Date of metamorphosis and mass at metamorphosis were positively correlated in both males and females (Fig. 1). Metamorphs recaptured as male adults $(n=261)$ had an average mass at metamorphosis of 4.65 $\pm 0.86 \mathrm{~g}$ (mean $\pm \mathrm{SD})$, a length of $32.61 \pm 2.13 \mathrm{~mm}$, and metamorphosed on average on 16 August (SD = $14.12 \mathrm{~d})$. The corresponding values for metamorphs recaptured as females $(n=206)$ were $4.49 \pm 0.87 \mathrm{~g}, 32.23$ $\pm 2.20 \mathrm{~mm}$, and 15 August $(\mathrm{SD}=13.82 \mathrm{~d})$. Because the spawning seasons lasted about one month (Hödl et al. 1997), some of the phenotypic variation in date of metamorphosis probably originated because not all tadpoles hatched on the same day.

Differences between males and females were significant when statistically controlling for among-year variation for mass and size (ANOVA including year; 
mass $F_{1,461}=8.12, P=0.004$; size $F_{1,461}=7.06, P=$ $0.008)$, but not for date $\left(F_{1,461}=0.66, P=0.418\right)$.

\section{Correlations between metamorphic traits and size at maturity}

Across all years, mass and size of spadefoot toads at maturity (defined as first capture as a breeder) differed significantly between sexes. Females were larger and heavier than males (male body mass $=10.14 \pm 2.39 \mathrm{~g}$ $[$ mean $\pm \mathrm{SD}]$, female body mass $=18.75 \pm 6.01 \mathrm{~g}, t_{256.67}$ $=19.38, P<0.001$; male length $=42.69 \pm 3.63 \mathrm{~mm}$, female length $=50.12 \pm 5.75 \mathrm{~mm}, t_{329.08}=16.17, P<$ 0.001). To describe body condition at maturity, we performed a principal component analysis from body mass and size for each sex separately. The first axis explained $>95 \%$ of the variance of size and body mass in both sexes and the scores were positively correlated with size and body mass in both sexes (loadings were 0.85 and 0.53 , respectively, for males; 0.72 and 0.69 , respectively, for females). In males, body condition at maturity $\left(\mathrm{PC}_{\mathrm{mat}}\right)$ was a nonlinear function of date of metamorphosis (Appendix B: Table B1; Fig. 1); predicted body condition at maturity was highest when metamorphosis occurred on 28 August (regression equation: $\mathrm{PC}_{\text {mat }}=$ $-194.0+1.652$ (date) $-0.0035\left(\right.$ date $\left.^{2}\right)$, where the standard errors of the regression coefficients are 38.3, 0.327, and 0.0007 , respectively; $n=261$ ). In females, body condition at maturity $\left(\mathrm{PC}_{\text {mat }}\right)$ depended positively on body condition at metamorphosis $\left(\mathrm{PC}_{\text {meta }}\right)$, and negatively on date (regression equation: $\mathrm{PC}_{\mathrm{mat}}=37.7+$ $1.71\left[\mathrm{PC}_{\text {meta }}\right]-0.17$ [date], where the standard errors of the regression coefficients are $11.60,0.50$, and 0.05 , respectively; $n=206$; Fig. 2 ). Yet, the best models only explained little of the observed variation (males, $r^{2}=$ 0.083; females, $r^{2}=0.055$ ).

\section{Recapture, age-specific breeding probabilities, and apparent survival}

Recapture probabilities.-Recapture probability was best represented by a time-dependent model (Appendix B: Table B2), which we used for subsequent steps, followed by a model that included also an additive sex effect. Other models clearly had no support. Annual recapture probabilities ranged from $0.55 \pm 0.05$ (mean $\pm \mathrm{SE})$ to $0.98 \pm 0.02$.

Age-specific breeding probabilities.-Modeling the age at which the probability of an as-yet-inexperienced breeder to reproduce is 1 clearly showed that full reproduction was at the age of 2 years in males, and 4 years in females (Appendix B: Table B3). These ages were used for further modeling.

Age-specific probabilities to reproduce for the first time were cohort dependent in males, but not in females (Appendix B: Table B4). When we inspected the estimates of the best model, we noted two unusual estimates. First, the probability of first-time breeding at age 1 year of the 1989 cohort of males was $0.68 \pm 0.29$, while the same parameter for males from cohorts 1990-1993 was in the
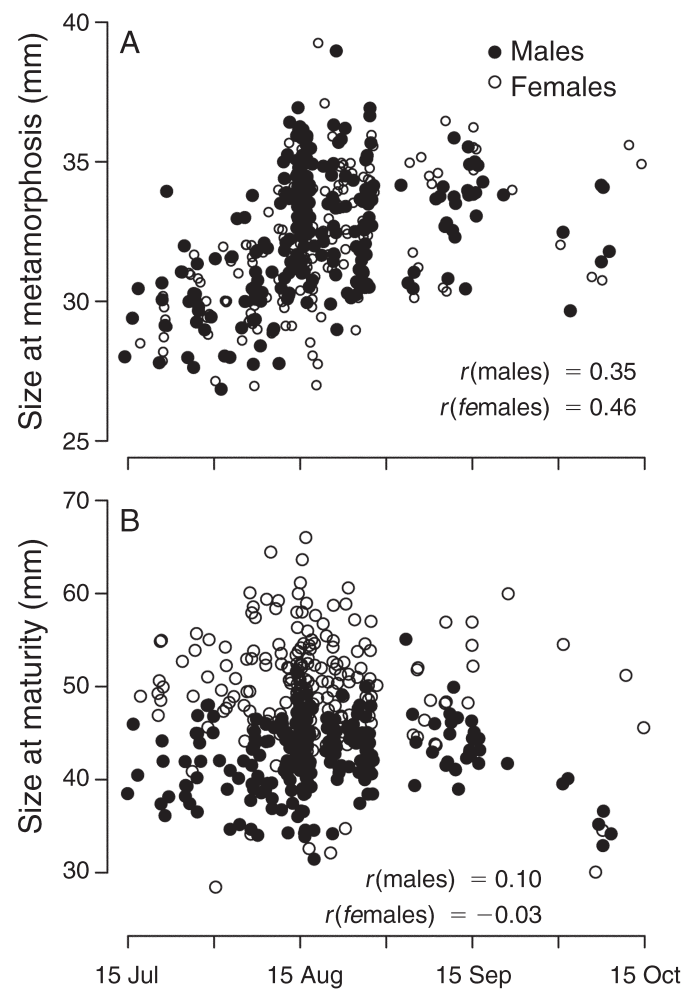

Date of metamorphosis

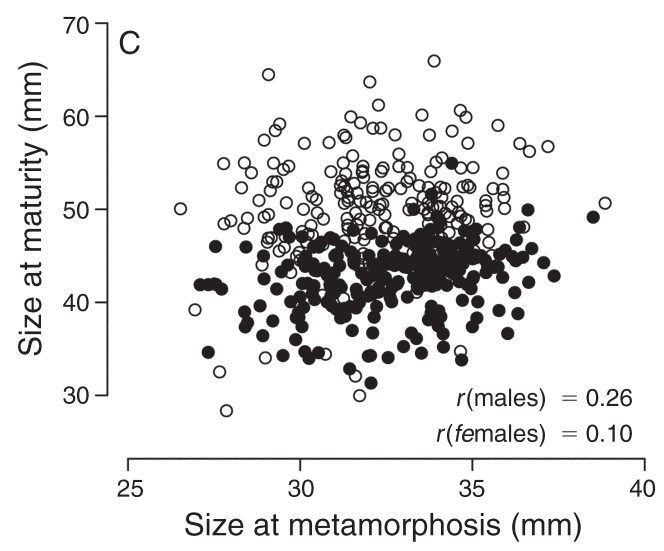

FIG. 1. The relationship between date of and size at metamorphosis and size at maturity. Only toads recaptured as adults, and thus with known sex, are included. Shown also is the correlation coefficient of each sex $(r)$. (A) Date of metamorphosis in relation to size at metamorphosis. (B) Date of metamorphosis in relation to size at maturity. (C) Size at metamorphosis in relation to size at maturity.

range of $0.00-0.12$ (with SE in the range of $0.00-0.05$ ). Second, the first-year survival probability of females of cohort 1989 was $1.00 \pm 0.00$ (profile likelihood confidence interval: $0.60-1.00$ ), and in the range from 0.37 to 0.57 for females from cohorts 1990 to 1993 (SE of 0.08 to 0.12). Since the deviance of the models changes when these two parameters are fixed to some arbitrary values, 

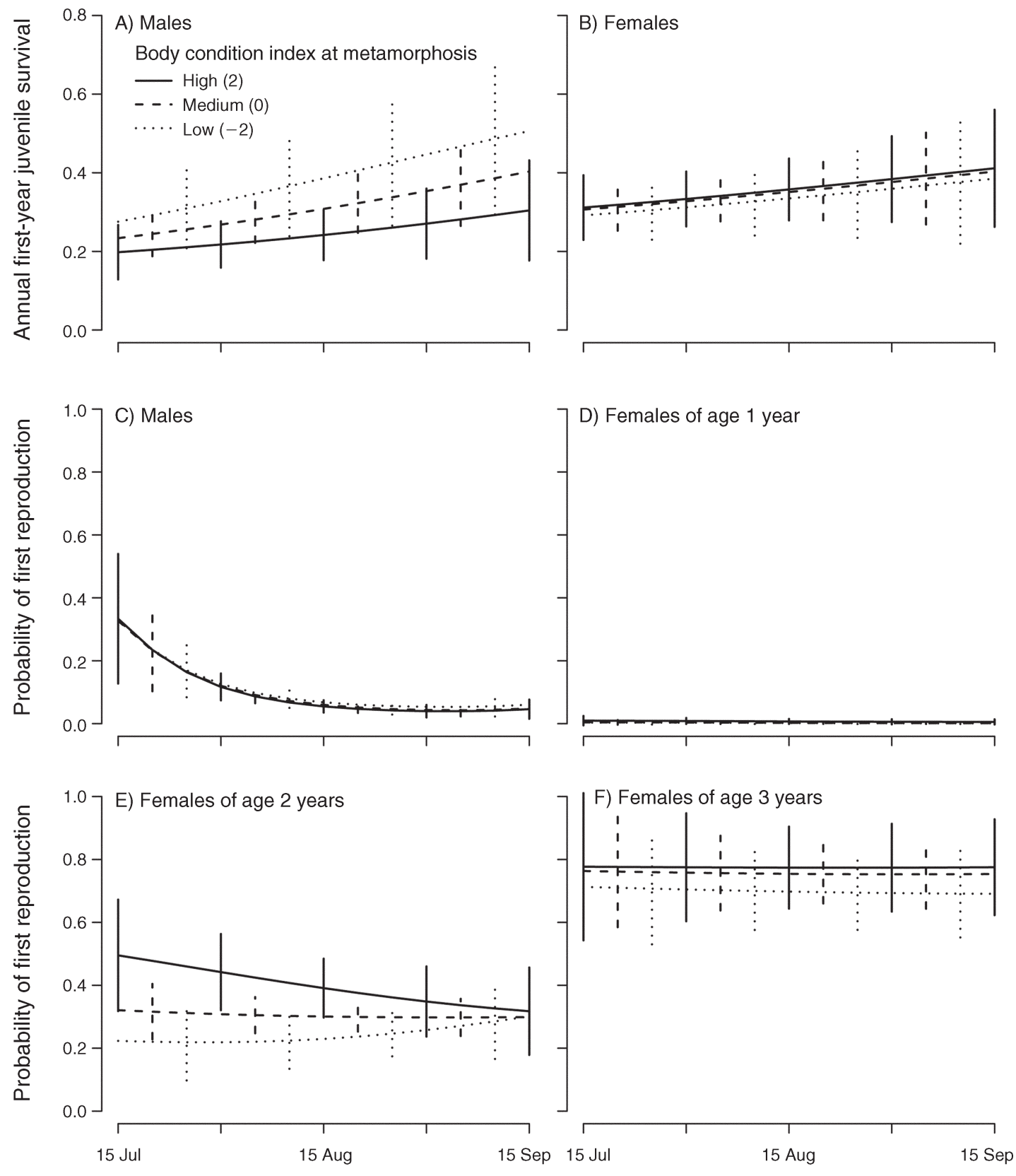

\section{Date of metamorphosis}

FIG. 2. Juvenile life history traits. All estimates are model-averaged probabilities. The vertical lines represent standard errors of the estimates. (A, B) Estimates of (A) male and (B) female toad first-year survival as a function of the date of and body condition at metamorphosis $\left(\mathrm{PC}_{\text {meta }}\right)$. Estimates are for the year 1990. Results for other years are similar, as year is an additive effect on date and body condition at maturity (Appendix B: Table B10). (C) Probability of first reproduction one year after metamorphosis for male toads in relation to body condition at and date of metamorphosis. (D) Probability of first reproduction one year after metamorphosis for female toads in relation to body condition at and date of metamorphosis. (E) Probability of first reproduction two years after metamorphosis for female toads in relation to body condition at and date of metamorphosis. (F) Probability of first reproduction three years after metamorphosis for female toads in relation to body condition at and date of metamorphosis.

the parameters were estimable. As these odd estimates can have an impact on model selection if they are included in models with specific constraints, we rerun the analysis allowing these two parameters to vary freely and modeling only the other parameters.
The a posteriori model selection (Appendix B: Table B6) showed that the age-specific breeding probability of males at age 1 year was the same for all cohorts (19901993). Very few males reproduced in the first year after metamorphosis $(0.08 \pm 0.03)$; all reproduced at the 
latest at age 2. In females, no female reproduced at age 1. Thereafter, age-specific breeding probabilities increased to $0.32 \pm 0.05,0.74 \pm 0.08$, and finally 1.00 with age 4 .

Apparent survival.-Model selection of survival revealed that first-year juvenile survival varied among years and differed between the sexes (Appendix B: Table B5). Adult (i.e., after first-year) survival was also variable among years, but the sex effect was additive. Because the estimates of juvenile first-year and adult survival were very close, we evaluated a posteriori whether they differ (Appendix B: Table B6). The model where juvenile first-year and adult survival were identical received the highest support from the data. Survival varied among years and was consistently higher in females than in males (difference on logit scale: $0.34 \pm 0.08)$.

\section{Impact of body condition and date of metamorphosis on age of first reproduction}

We modeled the impact of body condition at and date of metamorphosis on the age-specific probabilities of first time reproduction separately for each sex. In males, model selection showed that the probability to reproduce for the first time at age of 1 year was best described by a non-linear function of the date at metamorphosis (Appendix B: Table B7; Fig. 2B). Models including body condition at metamorphosis had very little support. Males that metamorphosed very early in the season had the highest probability to breed at age 1 year; but then the age-specific breeding probability was almost constant over a wide range of different dates of metamorphosis (Fig. 2B).

In females, the probability of first reproduction at ages 1 and 3 years depended only weakly on body condition or date of metamorphosis; in fact, only the second-best model included body condition at metamorphosis (Appendix B: Table B8). At age 2, a model including body condition at metamorphosis and date of metamorphosis was best supported by the data; this model was almost tied with a model that included only body condition at metamorphosis (Appendix B: Table B8). We then modeled body condition and date of metamorphosis as additive effects across all ages. Model selection revealed that body condition had an effect on the probability of first reproduction (Appendix B: Table B9). Model-averaged estimates for each age showed however that the effect of individual covariates on the probability of first time breeding was rather weak (Fig. 2).

\section{Impact of body condition and date of metamorphosis on first-year juvenile survival}

We modeled the effects of individual covariates as additive effects to the time-dependent first-year juvenile survival probabilities. In males, the best model contained the additive effects of date and body condition (Appendix B: Table B10), whereas in females the best model contained only an effect of time. Model-averaged estimates show that juvenile first-year survival was higher when toads metamorphosed later in the season. This effect was stronger in males than in females. In males, it is also apparent that a higher body condition resulted in lower survival probabilities, an effect that was most pronounced at late metamorphosis (Fig. 2A). First-year juvenile survival is survival from metamorphosis to the next year. Early and late metamorphosing toads may simply differ in juvenile survival because early metamorphosing spend more time in the terrestrial environment (i.e., daily survival may be the same but the number of days in the terrestrial environment differs).

\section{Probability to survive to maturity and population growth rates}

Males with low body condition at metamorphosis had a higher probability to survive to maturity than males with high body condition (Fig. 3A). The model predicted that early and late dates of metamorphosis were better for survival than average dates. However, there was a positive correlation between date of and size at metamorphosis (Fig. 1A). Hence, only few combinations of date and body condition occurred: early metamorphosis at low condition, metamorphosis at an intermediate date and body condition and late metamorphosis at high condition. There was a tendency (considering the width of the confidence interval), that males that underwent metamorphosis early at a low condition had the highest probability to reach maturity. All other combinations of date of metamorphosis and size at metamorphosis that occurred had lower, but similar probabilities to reach maturity (Fig. 3A). Because few toad metamorphosed very early in the season (15 July, see Fig. 1A), the vast majority of metamorphs had similar probabilities to reach maturity.

The population growth rates (i.e., fitness of females in relation to size at and date of metamorphosis) decreased with decreasing body condition and increased with increasing date of metamorphosis (Fig. 3). There was a tendency (given the width of the confidence intervals) that female toads metamorphosing early in the season at a low body condition had the lowest predicted population growth rate. Other typical combinations of body condition at and date of metamorphosis had similar predicted population growth rates. Since few toads metamorphosed early in the season (15 July, see Fig. 1), the vast majority of metamorphs had similar probabilities to reach maturity.

\section{DisCUSSION}

There was substantial variation in the metamorphic phenotype, as measured by size at and date of metamorphosis. This variation caused variation in post-metamorphic life history traits of juvenile spadefoot toads that depended on the sex of the toadlet (Fig. $2,3)$. Phenotypic variation in metamorphic phenotype was similar to the variation observed in other field 

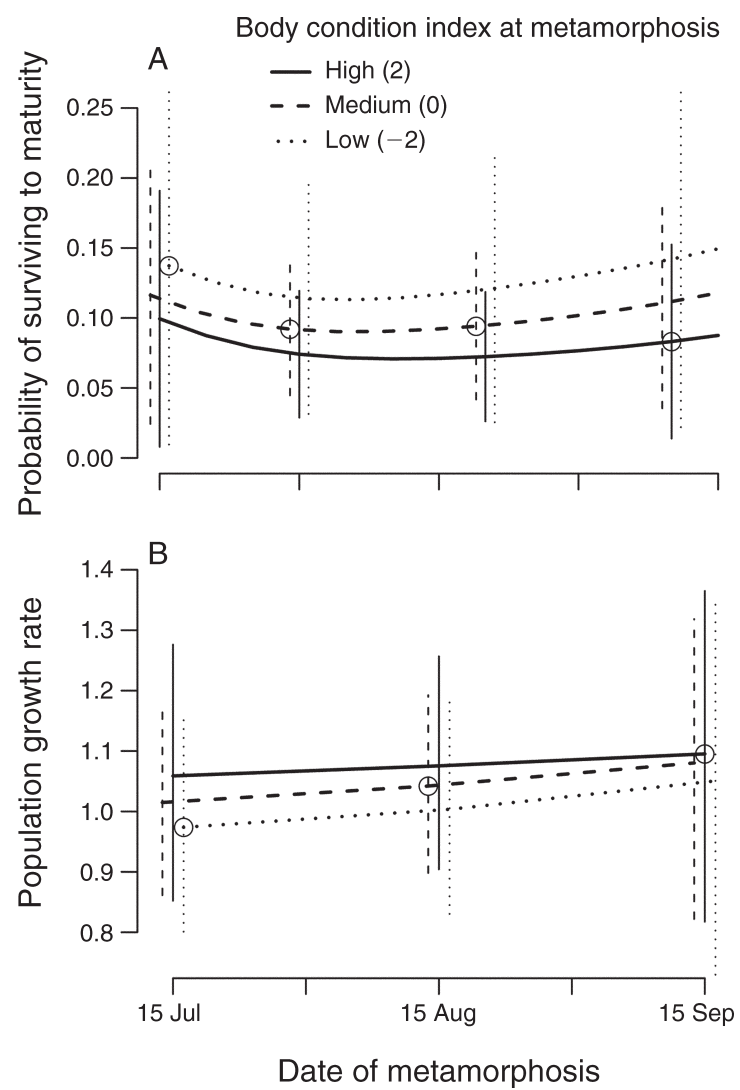

FIG. 3. Integrative measures of juvenile performance. (A) Probabilities of male spadefoot toads to survive to maturity (i.e., to reproduce at least once) in relation to body condition at $\left(\mathrm{PC}_{\text {meta }}\right)$ and date of metamorphosis, calculated from the model-averaged survival probabilities and age-specific probabilities to reproduce for the first time (from Fig. 2). The open circles indicate typical body conditions at metamorphosis $\left(\mathrm{PC}_{\text {meta }}\right)$ for a given date of metamorphosis (note that there is a significant positive correlation between body condition at metamorphosis and timing of metamorphosis). (B) Estimated population growth rates (fitness) of female spadefoot toads in relation to body condition ( $\left.\mathrm{PC}_{\text {meta }}\right)$ at and date of metamorphosis. Early metamorphosis corresponds to 14 July, medium metamorphosis to 8 August, and late metamorphosis to 12 September. Details about the model are provided in Appendix D. The open circles indicate the most frequent combinations of metamorphic traits (note that there is a significant positive correlation between body condition at metamorphosis and timing of metamorphosis). The vertical lines show the limits of the $95 \%$ confidence intervals.

studies (Smith 1987, Semlitsch et al. 1988). The previously described positive phenotypic correlations between metamorphic, juvenile, and adult life-history traits (Smith 1987, Semlitsch et al. 1988, Berven 1990, Goater 1994, Scott 1994, Morey and Reznick 2001, Altwegg and Reyer 2003, Chelgren et al. 2006) were only confirmed when we looked at one trait at a time. Yet, because disadvantages in one trait can be cancelled out by other traits (Dobzhansky 1956), more integrative fitness measures, such as the probability to reach maturity and population growth rate, are necessary
(McPeek and Peckarsky 1998). These fitness measures yielded a different insight than the analysis of single traits. In males, toads that metamorphosed very early at a small size had a higher probability to survive to maturity than toads that metamorphosed at a later date and larger size (Fig. 3). Female toads that metamorphosed early at a low body condition had the lowest predicted population growth. However, because very few male and female toads metamorphosed very early in the season (15 July, see Fig. 1), differences in metamorphic phenotype led to different life history pathways but in the end individuals that followed different life history pathways had equal population growth rates (females) or probabilities to reach maturity (males; Fig. 3). Thus, starting post-metamorphic size at a small size, a "bad start," did not lead to lower overall probability to reach maturity (males) or population growth rates (females).

Date of metamorphosis and size at metamorphosis correlated with the life history traits of juveniles in a sexspecific manner (Fig. 2). In male juvenile spadefoot toads, there was a positive relationship between late metamorphosis and the survival to the next year; the reason may be that early metamorphosing toads spent more time in the terrestrial environment. Male metamorphs with high body condition had lower juvenile first-year survival, whereas early metamorphosis resulted in early maturity, a result that is in line with previous studies. This resulted in a pattern of directional selection on body condition at metamorphosis and disruptive selection on timing of metamorphosis, the latter is determined by both growth and developmental rate.

Female juvenile life histories differed from males (Fig. 2). Predicted population growth rate of female metamorphs with high body condition was higher than predicted life time fitness of female metamorphs with an average or low body condition (Fig. 3). Survival was independent of body condition. Timing of metamorphosis had a weak effect on the age of maturity but was correlated positively with survival. Late metamorphosis resulted in higher life time fitness. Because there was a positive correlation between the size at and date of metamorphosis (Fig. 1A), the effects of body condition on population growth rate and the effect of date of metamorphosis on population growth rate largely cancelled each other out (Fig. 3B). As a consequence, different metamorphic phenotypes performed equally well.

Similar to our results, a number of authors report that larger size at or earlier date of metamorphosis did not lead to enduring increased postmetamorphic performance (e.g., Beck and Congdon 1999, Boone 2005). A possible explanation for this is plasticity in growth rates where small individuals have elevated growth rates (Beck and Congdon 1999, Boone 2005). This would then lead to similar performance of individuals with different starting conditions (i.e., date of and size at metamorphosis). We found that large and small metamorphs had similar performance but the mecha- 


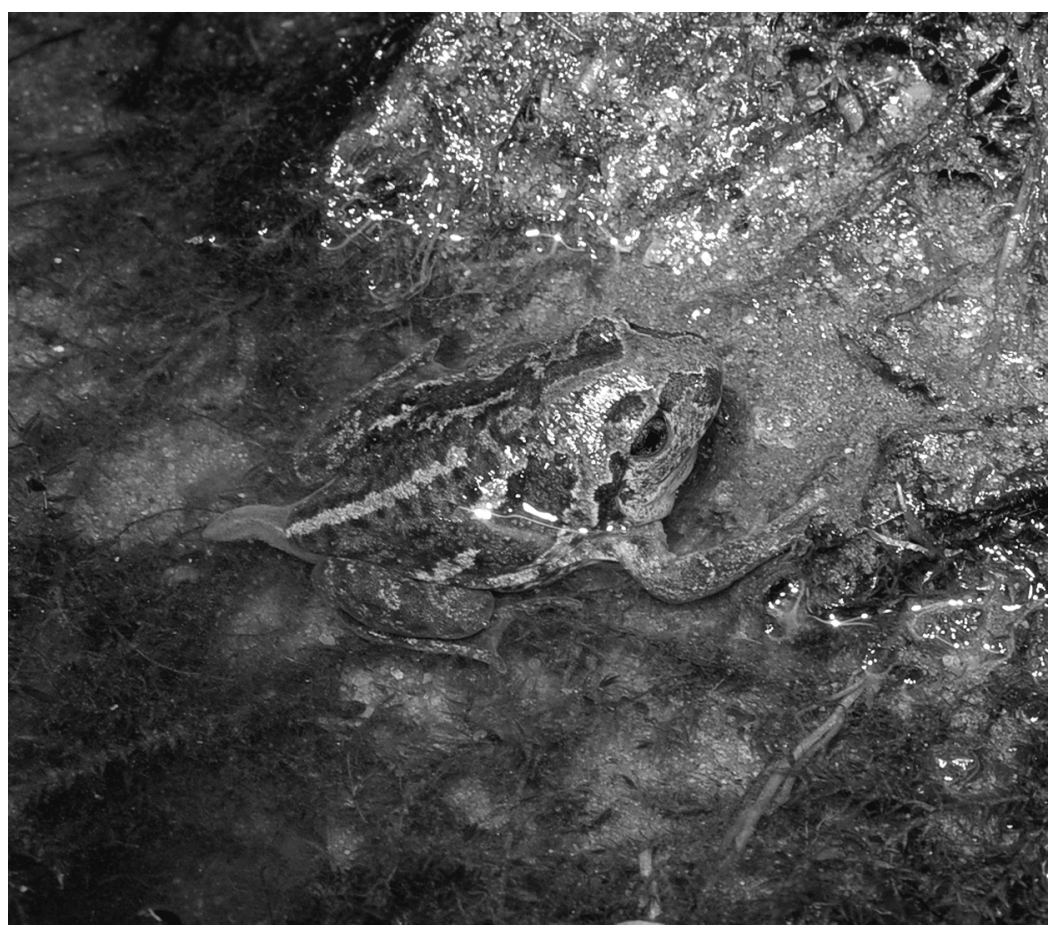

Plate 1. A spadefoot toad (Pelobates fuscus) undergoing metamorphosis. Photo credit: B. Thiesmeier.

nism was not plasticity in growth rates. Different starting conditions led to different life history pathways of similar performance where the effects of different dates of and sizes at metamorphosis cancelled each other out. Thus, there are multiple mechanisms how equal performance despite different dates of and sizes at metamorphosis may be attained. Most life history traits trade off (Dobzhansky 1956, Stearns 1992), so equal performance of different life history pathways may be also common. Many studies of compensatory growth have revealed some costs (Metcalfe and Monaghan 2001). In our case study, small individuals can cancel the effects of a bad start but there may be no costs because growth may not have to be accelerated.

If different combinations of date of and size at metamorphosis lead to different life history pathways with similar performance (probability to reach maturity and population growth rate), then this can contribute to the maintenance of phenotypic variation in metamorphic traits. Such phenotypic variation is known to abound in natural populations of species with complex life cycles (Wilbur and Collins 1973). We believe that natural selection may be more likely to maintain phenotypic variation in size at and timing of metamorphosis rather than to reduce it. We offer two nonmutually exclusive explanations.

The first explanation is based on the notion that the benefits of early and late maturity depend on population dynamics. Put simply, in a growing population, early maturity is favored whereas delayed maturity is favored in shrinking populations (Stearns 1992). Amphibian populations are notorious for strong fluctuations in size (Semlitsch et al. 1996, Meyer et al. 1998, Pellet et al. 2006). In years when the population is about to grow, early metamorphosis at a small size may be favored because it leads to early maturity. In other years when the population is about to become smaller, later metamorphosis at a larger size may be better because it leads to later maturity. Given the fact that amphibian populations fluctuate widely and different trait values are favored in different metamorphic cohorts, abundant phenotypic variation may persist. This scenario may suggest that small metamorphs pay a cost of being small at metamorphosis in shrinking populations because early maturity is disadvantageous. In contrast, large metamorphs may pay a cost of being large in growing populations because late maturity is disadvantageous.

The second explanation is based on the idea of "cohort iteroparity" (Wilbur and Rudolf 2006). In amphibians, there is often substantial variation in recruitment among years (Semlitsch et al. 1996). If there is strong variation in larval survival, then there is selection for decreased annual reproductive effort and higher adult survival (Seger and Brockmann 1987). An alternative to lengthening the adult life span may be to have offspring attain maturity in different years, a phenomenon termed "cohort iteroparity" by Wilbur and Rudolf (2006). This phenomenon is well-known for seed banks (Evans and Dennehy 2005). It may be an explanation as to why some amphibians have remarkably low adult survival despite high variability in reproductive success (Church et al. 2007). In conclusion, 
spreading offspring maturity may be beneficial and may explain why so much variation in metamorphic (and maturity) life history traits is maintained.

In agreement with previous studies, our results show that metamorphic phenotype correlated with postmetamorphic performance. However, different life history pathways converged to similar population growth rates (for females) and probability to reach maturity (for males). This result could only be detected through the use of integrative measures of performance. An analysis of one trait at a time would not have made evident that the effects on late and early metamorphosis at large or small size on postmetamorphic life history traits cancel each other out. We suggest that the similar performance of different life history pathways can be understood if a population dynamics perspective is included in the rationale. This perspective may explain how ample phenotypic variation may be maintained.

\section{ACKNOWLEDGMENTS}

We thank the many colleagues who collected data or helped with field work, the funding agencies that supported the project (a full list can be found in Hödl et al. 1997), and T. Flatt, R. Jehle, D. Reznick, and anonymous reviewers for comments on the manuscript. B. R. Schmidt was supported by the Basler Stiftung für biologische Forschung, the Forschungskredit of the University of Zürich, and the MAVA Fondation.

\section{Literature Cited}

Altwegg, R., and H.-U. Reyer. 2003. Patterns of natural selection on size at metamorphosis in water frogs. Evolution 57:872-882.

Auer, S. K. 2010. Phenotypic plasticity in adult life-history strategies compensates for a poor start in life in Trinidadian guppies (Poecilia reticulata). American Naturalist 176:818829.

Beck, C. W., and J. D. Congdon. 1999. Effects of individual variation in age and size at metamorphosis on growth and survivorship of southern toad (Bufo terrestris) metamorphs. Canadian Journal of Zoology 77:944-951.

Beckerman, A., T. G. Benton, E. Ranta, V. Kaitala, and P. Lundberg. 2002. Population dynamic consequences of delayed life-history effects. Trends in Ecology and Evolution 17:263-269.

Bell, G. 1977. The life of the smooth newt (Triturus vulgaris) after metamorphosis. Ecological Monographs 47:279-299.

Benard, M. F. 2004. Predator-induced phenotypic plasticity in organisms with complex life cycles. Annual Review of Ecology, Evolution and Systematics 35:651-673.

Berven, K. A. 1990. Factors affecting population fluctuations in larval and adult stages of the wood frog (Rana sylvatica). Ecology 71:1599-1608.

Boone, M. D. 2005. Juvenile frogs compensate for small metamorph size with terrestrial growth: overcoming the effects of larval density and insecticide exposure. Journal of Herpetology 39:416-423.

Burnham, K. P., and D. R. Anderson. 2002. Model selection and multi-model inference. Springer Verlag, Berlin, Germany.

Cam, E., E. G. Cooch, and J. Y. Monnat. 2005. Earlier recruitment or earlier death? On the assumption of equal survival in recruitment studies. Ecological Monographs 75:419-434.

Cam, E., J. Y. Monnat, and J. E. Hines. 2003. Long-term fitness consequences of early conditions in the kittiwake. Journal of Animal Ecology 72:411-424.
Caswell, H. 2001. Matrix population models: construction, analysis and interpretation. Second edition. Sinauer, Sunderland, Massachusetts, USA.

Chelgren, N. D., D. K. Rosenberg, S. S. Heppell, and A. I. Gitelman. 2006. Carryover aquatic effects on survival of metamorphic frogs during pond emigration. Ecological Applications 16:250-261.

Choquet, R., J.-D. Lebreton, O. Gimenez, A.-M. Reboulet, and R. Pradel. 2009. U-CARE: utilities for performing goodness of fit tests and manipulating capture-recapture data. Ecography 32:1071-1074.

Church, D. R., L. L. Bailey, H. M. Wilbur, W. L. Kendall, and J. E. Hines. 2007. Iteroparity in the variable environment of the salamander Ambystoma tigrinum. Ecology 88:891-903.

Clobert, J., J.-D. Lebreton, D. Allainé, and J.-M. Gaillard. 1994. The estimation of age-specific breeding probabilities from recaptures or resightings in vertebrate populations: II longitudinal models. Biometrics 50:375-387.

Conroy, S. D. S., and B. W. Brook. 2003. Demographic sensitivity and persistence of the threatened white- and orange-bellied frogs of Western Australia. Population Ecology 45:105-114.

De Block, M., and R. Stoks. 2005. Fitness effects from egg to reproduction: bridging the life history transitions. Ecology 86:185-197.

Dobzhansky, T. 1956. What is an adaptive trait? American Naturalist 90:337-347.

Evans, M. E. K., and J. J. Dennehy. 2005. Germ banking: bethedging and variable release from egg and seed dormancy. Quarterly Review of Biology 80:431-451.

Gibbons, J. W., and K. M. Andrews. 2004. PIT tagging: simple technology at its best. BioScience 54:447-454.

Goater, C. P. 1994. Growth and survival of postmetamorphic toads: interactions among larval history, density, and parasitism. Ecology 75:2264-2274.

Hels, T. 2002. Population dynamics in a Danish metapopulation of spadefoot toads Pelobates fuscus. Ecography 25:303313.

Hels, T., and G. Nachman. 2002. Simulating viability of a spadefoot toad Pelobates fuscus metapopulation in a landscape fragmented by a road. Ecography 25:730-744.

Hödl, W., R. Jehle, and G. Gollmann, editors. 1997. Populationsbiologie von Amphibien: Eine Langzeitstudie auf der Wiener Donauinsel. Stapfia 51. Oberösterreichisches Landesmuseum, Linz, Austria.

Jehle, R., and W. Hödl. 1998. PITs versus patterns: effects of transponders on recapture rate and body condition of Danube crested newts (Triturus dobrogicus) and common spadefoot toads (Pelobates fuscus). Herpetological Journal $8: 181-186$

Jehle, R., W. Hödl, and A. Thonke. 1995. Structure and dynamics of central European amphibian populations: a comparison between Triturus dobrogicus (Amphibia, Urodela) and Pelobates fuscus (Amphibia, Anura). Australian Journal of Ecology 20:362-366.

Lampo, M., and G. A. De Leo. 1998. The invasion ecology of the toad Bufo marinus: from South America to Australia. Ecological Applications 8:388-396.

Lebreton, J.-D., J. D. Nichols, R. J. Barker, R. Pradel, and J. A. Spendelow. 2009. Modeling individual animal histories with multistate capture-recapture models. Advances in Ecological Research 41:87-173.

Lindström, J. 1999. Early development and fitness in birds and mammals. Trends in Ecology and Evolution 14:343-348.

McCaffery, R. M., and B. A. Maxell. 2010. Decreased winter severity increases viability of a montane frog population. Proceedings of the National Academy of Sciences USA 107:8644-8649.

McPeek, M. A., and B. L. Peckarsky. 1998. Life histories and the strengths of species interactions: combining mortality, growth, and fecundity effects. Ecology 79:867-879. 
Metcalfe, N. B., and P. Monaghan. 2001. Compensation for a bad start: grow now, pay later? Trends in Ecology and Evolution 16:254-260.

Meyer, A. H., B. R. Schmidt, and K. Grossenbacher. 1998. Analysis of three amphibian populations with quartercentury long time-series. Proceedings of the Royal Society B 265:523-528.

Morey, S., and D. Reznick. 2001. Effects of larval density on postmetamorphic spadefoot toads (Spea hammondii). Ecology 82:510-522.

Pechenik, J. A. 2006. Larval experience and latent effectsmetamorphosis is not a new beginning. Integrative and Comparative Biology 3:323-333.

Pellet, J., B. R. Schmidt, F. Fivaz, N. Perrin, and K. Grossenbacher. 2006. Density, climate and varying return points: an analysis of long-term population fluctuations in the threatened European tree frog. Oecologia 149:65-71.

Pradel, R., and J.-D. Lebreton. 1999. Comparison of different approaches to the study of local recruitment of breeders. Bird Study 46 (Supplement):74-81.

R Development Core Team. 2009. R: a language and environment for statistical computing. R Foundation for Statistical Computing, Vienna, Austria. http://www. R-project.org

Schaub, M., R. Zink, H. Beissmann, F. Sarrazin, and R. Arlettaz. 2009. When to end releases in reintroduction programmes: demographic rates and population viability analysis of bearded vultures in the Alps. Journal of Applied Ecology 46:92-100.

Scott, D. E. 1994. The effects of larval density on adult demographic traits in Ambystoma opacum. Ecology 75:13831396.
Seger, J., and H. J. Brockmann. 1987. What is bet-hedging? Oxford Surveys in Evolutionary Biology 4:182-211.

Semlitsch, R. D., D. E. Scott, and J. H. K. Pechmann. 1988. Time and size at metamorphosis related to adult fitness in Ambystoma talpoideum. Ecology 69:184-192.

Semlitsch, R. D., D. E. Scott, J. H. K. Pechmann, and J. W. Gibbons. 1996. Structure and dynamics of an amphibian community: evidence from a 16-year study of a natural pond. Pages 217-248 in M. Cody and J. Smallwood, editors. Longterm studies of vertebrate communities. Academic Press, San Diego, California, USA.

Smith, D. C. 1987. Adult recruitment in chorus frogs: effects of size and date at metamorphosis. Ecology 68:344-350.

Stearns, S. C. 1992. The evolution of life histories. Oxford University Press, Oxford, UK.

Van Buskirk, J. 2003. Habitat partitioning in European and North American pond-breeding frogs and toads. Diversity and Distributions 9:399-410.

Werner, E. E. 1986. Amphibian metamorphosis: growth rate, predation risk, and the optimal size at transformation. American Naturalist 128:319-341.

White, G. C., and K. P. Burnham. 1999. Program MARK: survival estimation from populations of marked animals. Bird Study 46 (Supplement):120-139.

Wilbur, H. M. 1980. Complex life cycles. Annual Review of Ecology and Systematics 11:67-93.

Wilbur, H. M., and J. P. Collins. 1973. Ecological aspects of amphibian metamorphosis. Science 182:1305-1314.

Wilbur, H. M., and V. H. W. Rudolf. 2006. Life-history evolution in uncertain environments: bet hedging in time. American Naturalist 168:398-411.

\section{Supplemental Material}

\section{Appendix A}

Tables showing the number of first captures and recaptures of metamorphs, males, and females for the years 1989-1997 and body mass at metamorphosis, size at metamorphosis, and date of metamorphosis of male and female spadefoot toads for the years 1989-1993 (Ecological Archives E093-057-A1).

\section{Appendix B}

Tables showing model selection results for intermediate steps of the mark-recapture analysis (Ecological Archives E093-057-A2).

\section{Appendix C}

Description of the multistate mark-recapture model in matrix notation (Ecological Archives E093-057-A3).

Appendix D

Description of the projection matrix model (Ecological Archives E093-057-A4).

\section{Appendix E}

Results of a simulation study exploring the effects (i.e., absolute and relative bias) of an uneven sex ratio at metamorphosis on juvenile survival, adult survival, recapture probability, and probability to reproduce at an age of 1 year (Ecological Archives E093057-A5). 